http://ejournal.upi.edu/index.php/jaz - e-mail: jurnal.zonasi@gmail.com dan jurnal_zonasi@upi.edu doi.org/10.17509/jaz.v3i3.26502

\title{
SEKOLAH TINGGI MIGAS DURI DENGAN PENERAPAN PASSIVE COOLING
}

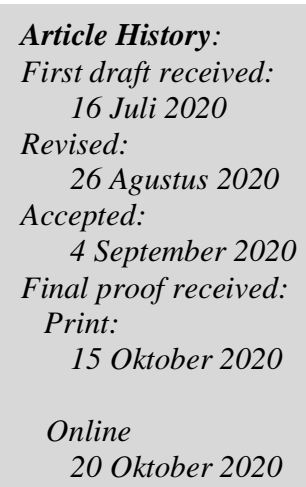

Jurnal Arsitektur ZONASI is indexed and listed in several databases:

SINTA 4 (Arjuna)

GARUDA (Garda Rujukan Digital)

Google Scholar

Dimensions

oneSearch

BASE

Member:
Crossref
RJI
APTARI
FJA (Forum Jurna Arsitektur)
IAI
AJPKM

\section{Rizky Hakiki ${ }^{1}$ \\ Pedia Aldy ${ }^{2}$ \\ Wahyu Hidayat ${ }^{3}$}

1,2,3 Universitas Riau, Pekanbaru, Indonesia

Kampus Bina Widya, Jl. HR. Soebrantas KM 12.5, Simpang Baru, Tampan, Kota Pekanbaru, Riau

Email: rizky.hakiki2015@student.unri.ac.id aldypedia@lecturer.unri.ac.id wahyu.hidayat@lecturer.unri.ac.id

Abstract: Oil and gas high school is a university that organizes academic or vocational education within the scope of one scientific discipline, namely oil and gas. Air Conditioner use is widely used to control temperature, and humidity of air in a room, to achieve the thermal comfort level of its users. Increased use of AC causes an increase in demand for energy consumption. Plus the issue of increasing population in Duri City, also increasing development, has caused the average temperature in Duri City to increase. Passive cooling is a very appropriate choice with the thermal conditions in Duri City. Passive cooling is the process of lowering the temperature of the room inside to an ideal temperature with a natural process without excessive use of electronic devices. Architectural works in the form of oil and gas high schools with the application of passive cooling will solve the problematic lack of needs and comfortable educational facilities in the oil and gas sector in the city of Duri, Bengkalis Regency. This research was conducted to obtain complex data regarding the location of the research. The survey was conducted by looking at the conditions around the site, the direction of movement of the sun and wind. From the results of the study will be processed to produce the needs of land use, the area to be used, and the application of the principle of passive cooling. The results of the analysis will produce a solution to the problem that is the design considerations that follow the rules of passive cooling.

Keywords: Education, Oil and Gas High School, Passive Cooling

Abstrak: Sekolah tinggi migas merupakan perguruan tinggi yang menyelenggarakan pendidikan akademik atau vokasi dalam lingkup satu disiplin ilmu pengetahuan yaitu migas. penggunaan Air Conditioner banyak digunakan untuk mengrontrol suhu, dan kelembaban udara dalam sebuah ruangan, untuk mencapai tingkat kenyamanan termal penggunanya. Peningkatan penggunaan AC menyebabkan peningkatan permintaan dalam mengkonsumsi energi. Ditambah lagi isu peningkatan populasi penduduk di Kota Duri, juga meningkatkan pembangunan, telah menyebabkan suhu rata-rata di Kota Duri meningkat. Passive cooling menjadi pilihan yang sangat tepat dengan kondisi termal yang ada di Kota Duri. Passive cooling adalah proses menurunkan temperatur ruang dalam hingga berada dalam temperatur ideal dengan proses alami tanpa penggunaan alat elektronik yang berlebihan. Karya arsitektur berupa sekolah tinggi migas dengan penerapan passive cooling akan memecahkan problematic kurang kebutuhan serta fasilitas pendidikan yang nyaman dibidang migas pada daerah kota Duri,Kabupaten Bengkalis. Penelitian ini dilakukan untuk mendapatkan data yang kompleks mengenai lokasi yang akan di lakukan penelitian. Survey dilakuan dengan melihat kondisi sekitar site ,arah pergerakan matahari, dan angin. Dari hasil penelitian akan diolah untuk menghasilkan kebutuhan dari penggunaan lahan, luasan yang akan di gunakan, dan penerapan dari prinsip passive cooling. Hasil analisa akan menghasilkan solusi dari permasalahan yaitu pertimbangan desain yang mengikuti dari kaidah passive cooling.

Kata Kunci: Passive Cooling, Pendidikan, Sekolah Tinggi Migas. 


\section{Pendahuluan}

Indonesia memiliki kekayaan sumber daya alam yang melimpah, salah satunya minyak. Dengan kekayaan sumber daya alam minyak yang berlimpah, Indonesia memiliki prospek dan peluang besar dalam pertumbuhan ekonomi yang diharapkan dapat menjadi salah satu penghasil miyak terbesar di Asia. Akan tetapi, besaran potensi sumber daya alam di Indonesia belum berbanding lurus dengan apa yang di harapkan dan cenderung tidak stabil dalam pendapatan sektor minyak, baik untuk kebutuhan dalam negeri maupun ekspor luar negeri. Faktor itu disebabkan kurangnya fasilitas maupun sumber daya manusia.

Provinsi Riau yang terletak di tengah pulau Sumatera memiliki kekayaan alam baik di dalam perut bumi maupun di permukaan bumi, dan Kekayaan alam di perut bumi provinsi Riau adalah minyak. Riau memiliki wilayah penghasil minyak yang disebut wilayah kerja Blok Rokan. Salah satu wilayah kerja Blok Rokan ialah kota Duri. Duri adalah salah satu kecamatan terkaya di Indonesia. Bagaimana tidak, Orangorang banyak menyebut kota Duri dengan sebutan "kota Atas minyak Bawah minyak", maksud dari katakata tersebut ialah minyak bumi dan minyak sawit.

Kota Duri sendiri merupakan wilayah kerja Blok Rokan yang termasuk penghasil minyak terbesar dan letak strategisnya sebagai kawasan yang berbasis pusat pendidikan di provinsi Riau. Kota Duri yang merupakan wilayah kerja Blok Rokan punya kontribusi besar dalam export minyak dunia dan menyumbang sekitar $60 \%$ produksi minyak mentah di Indonesia. produksi saat ini ialah 207,000 Barel perhari. Minyak mentah yang di hasilkan ladang minyak Duri merupakan salah satu minyak kualitas terbaik di Dunia,yakni Duri Crude pada bulan November 2006 dan Duri Steam Flood Field mencapai rekor produksi 2 Miliyar Barel sejak pertama dieksplorasi pada 1958. Hal ini karena $90 \%$ wilayahnya merupakan penghasil minyak dibawah naungan PT.Chevron Pasific Indonesia (CPI). (Kementerian Energi dan Sumber Daya Mineral).

CPI terus mengembangkan lapangan ini untuk menjaga kontribusi Lapangan Duri terhadap produksi nasional. Dua pengembangan terakhir adalah North Duri Area 12 dan 13 yang masing-masing menghasilkan produksi perdana pada 2008 dan 2013. (Kumparan.com, 2018) Dengan sejarah dan realita yang ada, bahwa diperlukannya sarana pendidikan yang berbasis migas di kota Duri.

Perancangan sekolah tinggi migas di Duri merupakan sebuah wujud solusi dalam menghadapi pesatnya perkembangan teknologi revolusi industri 4.0 dimana pengolahan migas Duri yang merupakan wilayah kerja Blok Rokan pada tahun 2021 ke atas akan di olah oleh PT.Pertamina dan diharapkan dapat meningkatkan sumber daya manusia di provinsi Riau dalam hal migas. (Kementerian Energi dan Sumber Daya Mineral) Fasilitas pendidikan ini memiliki peluang yang besar untuk berkembang sebagai salah satu cara untuk menambah dan mempertahankan sumber daya manusia dalam bidang migas yang akan datang. Dengan isu peningkatan populasi dan pembangunan di kota Duri hal itu menyebabkan suhu rata-rata di kota Duri meningkat.

Sebuah bangunan pendidikan akan menghabiskan cukup banyak energi yang digunakan, umumnya untuk pencahayaan buatan, dan penghawaan buatan. Hal ini tentunya menjadi pertimbangan yang cukup penting dalam perancangan, mengetahui fenomena krisis energi yang saat ini sedang terjadi.

Dalam 10 tahun terakhir, penggunaan Air Conditioner banyak digunakan untuk mengontrol suhu, dan kelembaban udara dalam sebuah ruangan, untuk mencapai tingkat kenyamanan termal penggunanya. Peningkatan penggunaan AC menyebabkan peningkatan permintaan dalam mengkonsumsi energi. Ditambah lagi isu peningkatan populasi penduduk di Kota Duri, juga meningkatkan pembangunan, telah menyebabkan suhu rata-rata di Kota Duri meningkat. (Vinosa, 2017)

Passive cooling menjadi pilihan yang sangat tepat dengan kondisi termal yang ada di kota Duri. Passive cooling adalah proses menurunkan temperatur ruang dalam hingga berada dalam temperatur ideal dengan proses alami tanpa penggunaan alat elektronik yang berlebihan. Proses ini membutuhkan energi dan biaya yang jauh lebih sedikit dibandingkan dengan menggunakan metode lain (misalnya penggunaan pendingin ruangan). Prinsip kerjanya juga sederhana, yaitu mengurangi panas yang terserap oleh bangunan dan menghilangkan panas berlebih yang tersimpan pada bangunan.

Passive cooling memiliki beberapa prinsip yang mendasari dalam pengaplikasian, yaitu heat avoidance, heat removal, dan comfort zone shift/extend. Heat avoidance adalah prinsip perlindungan yang menghindarkan pemanasan kulit luar gedung (Frick \& Sukisyanto,2007). Sedangkan heat removal prinsip adalah pendinginan pasif yang bertumpu pada pembuangan panas dari dalam gedung ke heat sink alami (Prasetyo,2018). Dan comfort zone shift/extend adalah prinsip pendinginan yang menggeser atau memperluas daerah nyaman atau comfort zone dengan pergerakan udara (Frick \& Sukisyanto,2007) 
Dalam pengaplikasian passive cooling pada bangunan, aliran udara menjadi hal yang penting. Aliran udara akan terjadi ketika angin yang berada di luar menghantam bagian dari sisi benda dan menghasilkan tekanan positif. Pada diwaktu yang sama, udara yang menghantam sisi benda akan terisap pada sisi yang terhindar dari angin, sehingga menciptakan tekanan negative, Terdapat empat tipe dasar aliran udara meliputi arus berlapis (laminar), terpisah (separate), bergolak (turbulent), dan berpusar (eddy).
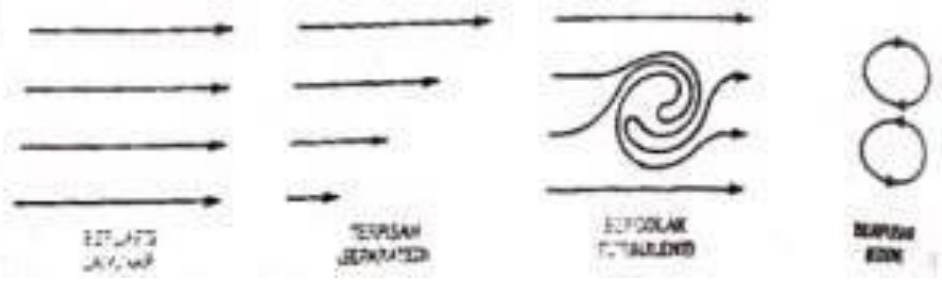

Gambar 1. Empat Jenis Aliran Angin

Sumber: Bowen, 1981 dalam Lechner, 2001

Adapun beberapa teknik passive cooling, sebagai berikut :

\begin{tabular}{|c|c|}
\hline Teknik & Keterangan \\
\hline External Shading & Sebagai penghalang matahari langsung untuk masuk kedalam bangunan. (Dogne,2016) \\
\hline Thermal Mass & $\begin{array}{l}\text { Merupakan pemilihan material, dimana memilih material yang menyimpan panas, namun } \\
\text { khusus daerah yang bersifat tropis sebaiknya yang memiliki nilai penyerapan panas yang } \\
\text { rendah. (Vinosa,2017) }\end{array}$ \\
\hline $\begin{array}{l}\text { Low Window to Wall } \\
\text { Area Ratio }\end{array}$ & Merupakan rasio besaran bukaan yang digunakan pada dinding. (Vinosa,2017) \\
\hline Passive Ventilation & $\begin{array}{c}\text { Merupakan sistem pemanfaatan tekanan angin untuk Sistem penukaran udara pada } \\
\text { bangunan. (Vinosa,2017) }\end{array}$ \\
\hline Cross Ventilation & $\begin{array}{l}\text { Merupakan sistem penghawaan yang menggunakan kedua sisi bangunan yang bersebrangan. } \\
\text { (Prasetyo,2018) }\end{array}$ \\
\hline Orientation & $\begin{array}{c}\text { Merupakan arah hadap bangunan, hal ini dapat meminimalisir atau memaksimalkan } \\
\text { masuknya matahari dan angin pada bangunan. (Prasetyo,2018) }\end{array}$ \\
\hline Building Shape & $\begin{array}{c}\text { Merupakan bentukan dari bangunan, dimana bentukan bangunan sangat berpengaruh, } \\
\text { apabila bentukkan bangunan dapat mengikuti arah angin maka dapat memaksimalkan udara } \\
\text { yang masuk. (Prasetyo,2018) }\end{array}$ \\
\hline Double Fasade & $\begin{array}{c}\text { Merupakan lapisan kedua pada bangunan Dengan menggunakan system ini maka dapat } \\
\text { memanfaatkan ruang antara kedua kulit bangunan sebagai penyaring suhu panas yang masuk } \\
\text { kedalam bangunan. (Prasetyo,2018) }\end{array}$ \\
\hline Evaporative Cooling & $\begin{array}{l}\text { Merupakan teknik pendingin dimana udara outdoor di dinginkan dengan menguapkan air } \\
\text { sebelum dimasukkan ke dalam bangunan. (Gropius,1955) }\end{array}$ \\
\hline Earth Cooling Tubes & $\begin{array}{l}\text { Merupakan sistem tabung pendingin yang membawa udara luar ke dalam bangunan melalui } \\
\text { pipa bawah tanah. Efek pendingin ini tergantung pada keberadaan perbedaan suhu luar dan } \\
\text { tanah di kedalaman tabung. (Sudiarta,2016) }\end{array}$ \\
\hline Stacked Window & $\begin{array}{l}\text { Merupakan sistem bukaan pada dinding yang sama (bawah dan atas), hal ini dapat } \\
\text { membantu memasukkan udara dari bukaan bawah dan membuang udara dari bukaan atas. } \\
\text { (Prasetyo,2018) }\end{array}$ \\
\hline $\begin{array}{l}\text { Central Atria and } \\
\quad \text { Lobbies }\end{array}$ & $\begin{array}{c}\text { Menggunakan atrium dan lobby yang besar pada rancangan agar dapat memusatkan } \\
\text { penhawaan pada titik tersebut, seperti memasukkan udara kemudian mengeluarkannya } \\
\text { melalui atrium, lobby, atau void tersebut. (Vinosa,2017) }\end{array}$ \\
\hline
\end{tabular}

Perancangan Sekolah Tinggi ini ditujukan untuk memenuhi kebutuhan, memperbaiki dan mengasah sumber daya manusia dalam bidang migas di provinsi Riau, dilain sisi belum adanya fasilitas pendidikan dalam bidang migas yang berada di kota Duri. Dengan adanya fasilitas pendidikan khusus migas diharapkan dapat menghasilkan sumber daya manusia dalam bidang migas yang dapat bersaing dengan sumber daya manusia daerah lain maupun luar negeri.

\section{Metode Penelitian}

Penelitian dilakuan berada di Jl. Komplek Pendidikan CPI ,desa Talang Mandi, kecamatan Mandau, kabupaten Bengkalis, Provinsi Riau menggunakan metode pengumpulan data dengan pengumpulan data primer dan data sekunder. Pengumpulan data primer di laksanakan dengan cara survey lapangan, 
dokumentasi lapangan, dan wawancara. Data sekunder berasal dari kajian jurnal, buku, skripsi, tesis, disertasi, dan media dengan pengumpulann hasil data yang berhubungan dengan penerapan passive cooling pada Sekolah Tinggi Migas Duri dengan membaca mengalanalisa dari penerapan prinsip passive cooling dan fungsi dari Sekolah Tinggi Migas (Gambar 2).

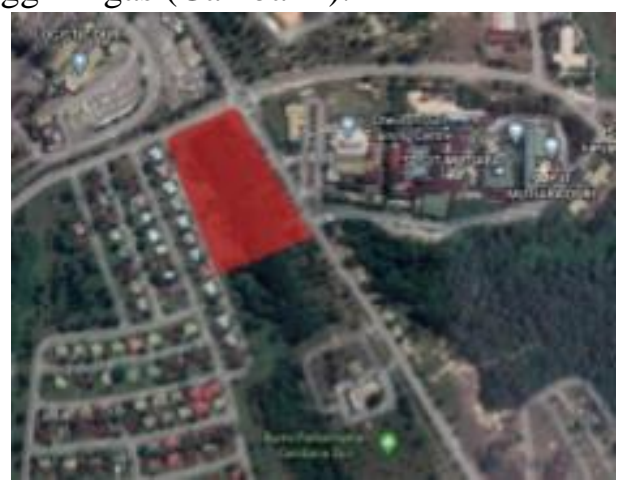

Gambar 2. Lokasi Site (Sumber: Google Earth 2020)

Tahapan dimulai dengan tahapan pencarian data pada jurnal. Tahapan selanjutnya yaitu melakukan tahapan survey lapangan dan dokumentasi lapangan. Pelaksanaan ini dilakukan untuk mendapatkan data yang kompleks mengenai lokasi yang akan di lakukan penelitian. Survey dilakuan dengan melihat kondisi tanah pada lokasi, kontur dari lahan, vegetasi di dalam dan sekitar lahan, dan kondisi sirkulasi di sekitar lokasi. Tahap analisis yaitu pengolahan data yang didapatkan berasal dari hasil survey lapangan dan dokumentasi yang selanjutnya di sesuaikan dengan kriteria dari penerapan prinsip passive cooling. Hasil dari analisa akan diolah untuk menghasilkan kebutuhan dari penggunaan lahan, luasan yang akan di gunakan, dan penerapan dari prinsip passive cooling. Hasil analisa akan menghasilkan solusi dari permasalahan yaitu pertimbangan desain yang mengikuti dari kaidah passive cooling. Hal itu menjadi pedoman dasar yang akan dikembangkan dalam tahapan perancangan. Dalam menuju tahapan perancangan, diperlukan penggunaan aplikasi dalam menganalisa dan pengoptimalan penerapan prinsip passive cooling pada tahapan perancangan. Aplikasi yang digunakan menggunakan aplikasi ecotect dalam menganalisa site dan bangunan yang akan dirancang, dan penggunaan aplikasi flow design dalam pembuktian pergerakan angin dalam perancangan menyesuaikan dari prinsip passive cooling.

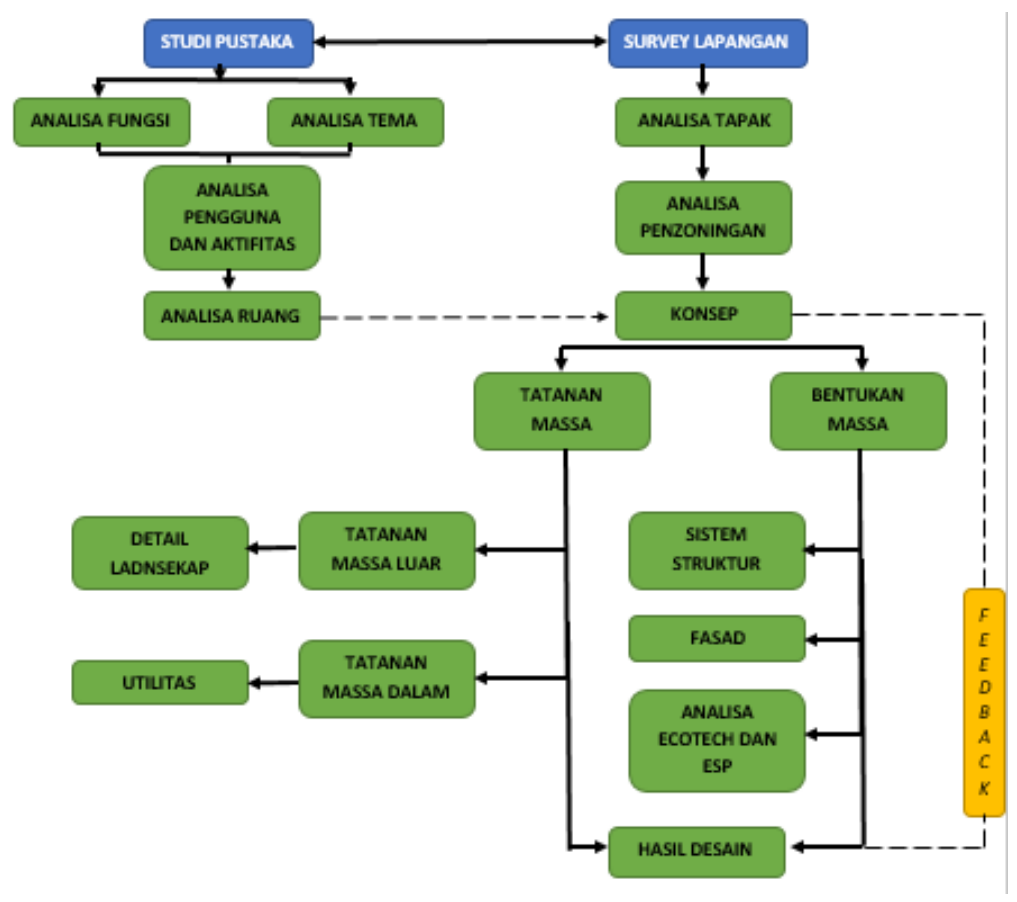

Gambar 3. Skema Alur

Sumber: Data Peneliti 2020 


\section{Hasil dan Pembahasan}

\subsection{Analisis}

\subsubsection{Lokasi Perancangan}

Lokasi berada di Jl. Komplek Pendidikan CPI ,desa Talang Mandi, kecamatan Mandau, kabupaten Bengkalis dengan data luas lahan $\pm 18.000 \mathrm{~m}^{2}$ (1,8 Ha), Koefisien Dasar Bangunan 50\% dan memiliki kontur tanah yang memiliki perbedaan leveling antara bagian tepi jalan dengan area lain pada site. Site merupakan lahan kosong milik PT Chevron Pasific Indonesia(CPI) dan dapat dijadikan sebagai sekolah tinggi migas. Pemilihan lokasi site di karenakan lokasi site merupakan area komplek PT Chevron Pasific Indonesia(CPI) hal ini dapat memudahkan dan menunjang kegiatan praktek lapangan dalam bidang migas.. Lokasi site memiliki batas administratif sebelah utara yang berbatasan dengan logistic Duri, sebelah timur berbatasan dengan Chevron Duri Training Centre, sebelah selatan berbatasan dengan Bumi Perkemahan Cendana Duri, dan sebelah barat berbatasan dengan Komplek perumahan CPI.

Berdasarkan RTRW Kabupaten Bengkalis perhitungan dari kebutuhan ruang yang di perlukan, luas lahan yang tersedia merupakan $18.000 \mathrm{~m} 2$ atau $1.8 \mathrm{Ha}$. jumlah luas total lahan sebesar $18.591 \mathrm{~m} 2$ yang terdiri dari $13.159 \mathrm{~m} 2$ luas bangunan, dan $5.432 \mathrm{~m} 2$ luas ruang luar. Dengan KDB sebesar 50\% maka dari luas site $1.8 \mathrm{Ha}$, KDB untuk bangunan yang akan dirancang sebesar $9.000 \mathrm{~m} 2$. Bangunan terdiri menjadi 1 sampai 3 lantai.

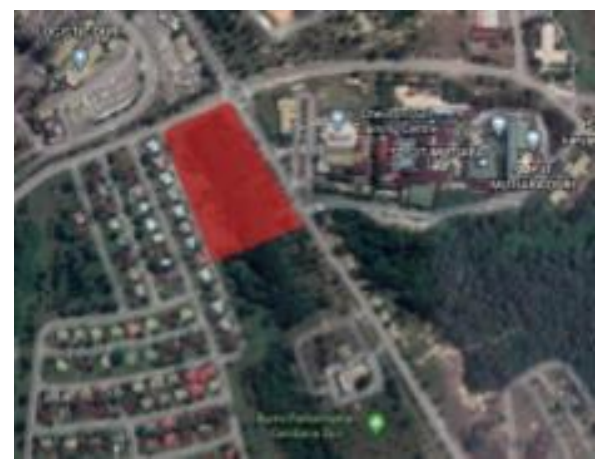

Gambar 4. Lokasi Site

Sumber: Google Earth 2020

\subsubsection{Kebutuhan Ruang}

Data besaran dari kebutuhan ruang pada Sekolah Tinggi Migas Duri dibagi menjadi empat fasilitas, yaitu fasilitas pendidikan, fasilitas pengelola dan administrasi, fasilitas penunjang, dan fasilitas servis. Perhitungan besaran ruang ini berdasarkan kepada Neufert Architect Data (NAD), Asumsi (A) berdasarkan studi banding.

Tabel 2.Kebutuhan Ruang

\begin{tabular}{|c|c|}
\hline Fasilitas & Luas \\
\hline Fasilitas Pendidikan & $3.569 \mathrm{~m} 2$ \\
\hline Fasilitas Pengelola dan & $1.157 \mathrm{~m} 2$ \\
\hline Fasilitas Penunjang & $8.135 \mathrm{~m} 2$ \\
\hline Fasilitas Servis & $298 \mathrm{~m} 2$ \\
\hline Ruang Luar & $5.432 \mathrm{~m} 2$ \\
\hline Total & $13.159 \mathrm{~m} 2$ \\
\hline
\end{tabular}

Berdasarkan RTRW Kabupaten Bengkalis, luas lahan yang tersedia merupakan $18.000 \mathrm{~m} 2$ atau 1.8 Ha. jumlah luas total lahan sebesar $18.591 \mathrm{~m} 2$ yang terdiri dari $13.159 \mathrm{~m} 2$ luas bangunan, dan $5.432 \mathrm{~m} 2$ luas ruang luar. Dengan KDB sebesar 50\% maka dari luas site 1.8 Ha, KDB untuk bangunan yang akan dirancang sebesar $9.000 \mathrm{~m} 2$. Bangunan terdiri menjadi 1 sampai 3 lantai.

\subsubsection{Aksebilitas dan Sirkulasi}

Aksesibilitas dari lokasi ini berada di area komplek PT Chevron Pasific Indonesia(CPI), sehingga mudah dijangkau oleh pengguna baik menggunakan kendaraan umum maupun kendaraan pribadi. Intensitas 
kendaraan pada jalur sekitar tapak tidak terlalu ramai hal itu dikerenakan yang berkepentingan saja yang dapat masuk ke area komplek CPI.

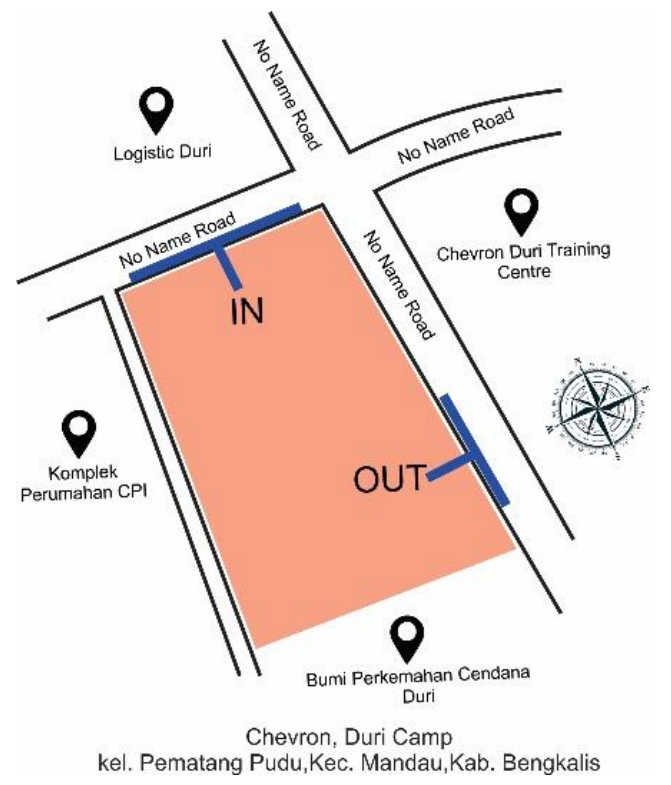

Gambar 5. Aksebilitas dan Sirkulasi Sumber: Data Peneliti 2020

\subsubsection{Visual}

Lokasi ini mememiliki potensi visual yang bagus. Pada arah selatan memiliki visual menghadap ke bumi perkemahan cendana Duri, dimana keadaan alam yang masih asri dan masih banyaknya tanaman yang dapat memberikan kenyamanan peserta didik dan pengunjung sekolah tinggi migas. Di sebelah Timur memiliki visual yang menghadap ke Chevron Duri Training Centre dan desikitarnya masih memiliki keadaan alam yang asri, dan pada sebelah timur juga bagi pengguna jalan yang melewati dapat melihat langsung ke arah bangunan. Dan pada arah barat memiliki visual yang menghadap Komplek perumahan CPI, yaitu perumahan yang di khususkan untuk pekerja CPI.

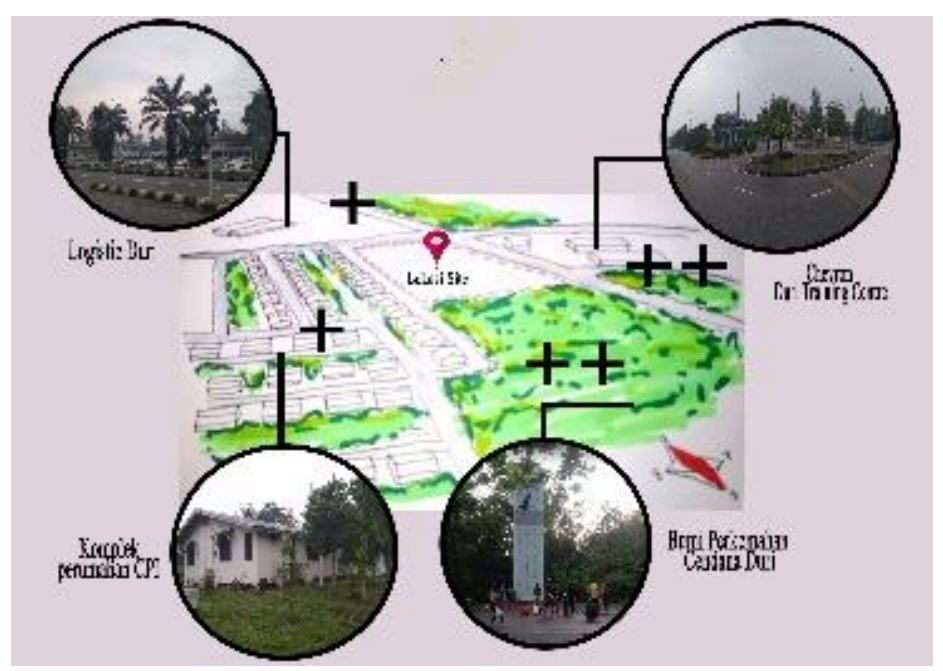

Gambar 6. Visual Lokasi Site

Sumber: Data peneliti 2020

\subsubsection{Kebisingan}

Pada lokasi site memiliki tingkat kebisingan yang berbeda. Dimana tingkat kebisingan tertinggi berada di bagian Timur dan Utara dikarenakan jalan yang ramai dilewati kendaraan dan aktfitas. Pada bagian Barat dan Selatan site memiliki tingkat kebisingan lebih rendah, yang berasal dari aktifitas pengunjung perkemahan pramuka dan pemukiman. 


\subsubsection{Matahari dan Angin}

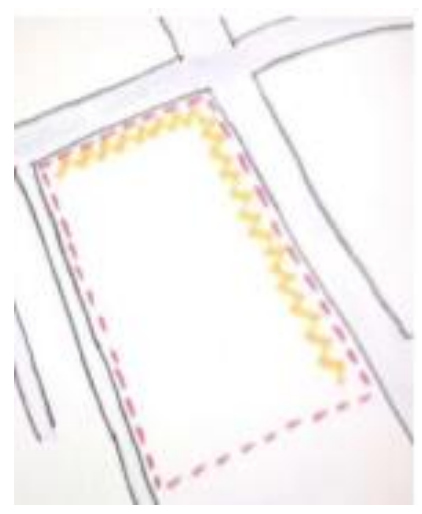

Gambar 7. Kebisingan

Sumber: Data Peneliti 2020

Lokasi site berada di Kota Duri yang memiliki iklim tropis. Dimana iklim tropois memiliki waktu edar matahari Selama 9-10 jam dalam sehari. Lokasi site berada diantara arah timur dan arah barat matahri, yang memiliki papacaran cahaya langsung dari matahari ke lokasi site.

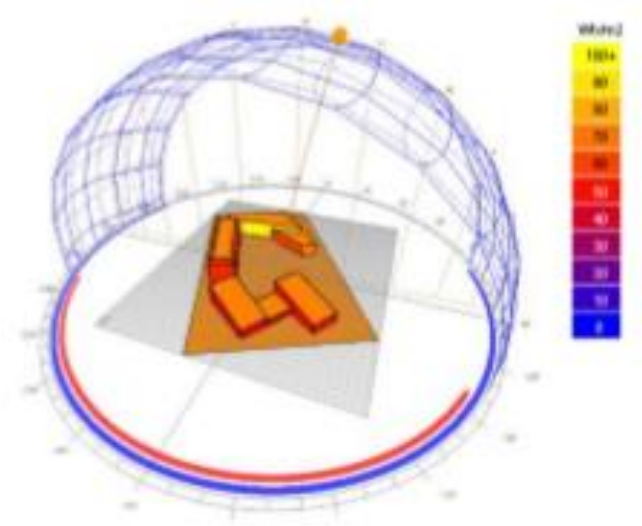

Gambar 8. Peredaran Matahari

Sumber: Data Peneliti 2020

Jalur pergerakan angin di Indonesia, terutama Kota Duri di pengaruhi dari angin muson timur dan barat. dan Kota Duri memiliki tingkat kelembapan yang tinggi. Pergerakan angin bergerak dominan dari timur tenggara dan selatan tenggara.

Tabel 3.Data Kecepatan dan Arah Angin Kota Duri

\begin{tabular}{|l|c|c|c|}
\hline Tahun & Bulan & $\begin{array}{c}\text { Kecapatan } \\
\text { Rata-Rata }\end{array}$ & Arah Rata-Rata \\
\hline $\mathbf{2 0 1 9}$ & JAN & 2.93 & Selatan Tenggara \\
\hline $\mathbf{2 0 1 9}$ & FEB & 3 & Timur \\
\hline $\mathbf{2 0 1 9}$ & MAR & 3.45 & Timur Tenggara \\
\hline $\mathbf{2 0 1 9}$ & APR & 2.6 & Tenggara \\
\hline $\mathbf{2 0 1 9}$ & MEI & 2.67 & Timur Tenggara \\
\hline $\mathbf{2 0 1 9}$ & JUN & 3.2 & Selatan \\
\hline $\mathbf{2 0 1 9}$ & JUL & 3.61 & Timur Tenggara \\
\hline $\mathbf{2 0 1 9}$ & AGU & 4.54 & Timur Tenggara \\
\hline $\mathbf{2 0 1 9}$ & SEP & 5.1 & Timur \\
\hline $\mathbf{2 0 1 9}$ & OKT & 3.5 & Tenggara \\
\hline $\mathbf{2 0 1 9}$ & NOV & 2.76 & Selatan Tenggara \\
\hline $\mathbf{2 0 1 9}$ & DES & 3.51 & Timur \\
\hline
\end{tabular}

Sumber: Meteoblue.com 2019

Berikut diagram wind rose Kota Duri berdasarkan konversi dari data kecepatan angin dan arah angin dari Meteoblue.com tahun 2019. 


\subsubsection{Konsep Dasar}

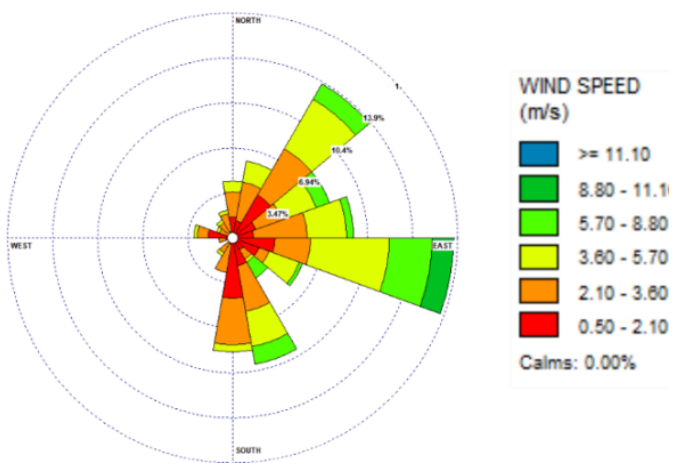

Gambar 9. Wind Rose Kota Duri

Sumber: Meteoblue.com 2019

Konsep dasar yang digunakan pada perancangan Sekolah Tinggi Migas adalah Petrolium Formation. Petrolium Formation merupakan proses bagaimana migas bisa terbentuk. Pemilihan konsep tersebut di karenakan Sekolah Tinggi Migas memiliki dasar ilmu yang membahas apa itu migas, bagaimana proses pembentukan migas dan pencabangan keberbagai ilmu dalam ruang lingkup migas.

Sesuai dengan prinsip dari passive cooling yang diimplementasikan dalam bangunan diharapkan dapat menghasilkan bangunan dengan penghawaan dan termal yang baik. Prinsip yang di terapkan tersebut menggunakan aliran atau pergerakan udara yang ditangkaap oleh bangunan dengan tujuan penghawaan atau pengaturan termal dalam bangunan. Konsep dari Petrolium Formation menerapkan prinsip passive cooling yang mana perancangannya tidak melupakan bagaimana cara penerapan prinsip passive cooling tersebut. Karena udara yang masuk kedalam bangunan akan memberikan kenyaman dalam hal penghawaan yang akan menghasilkan kenyaman bagi pengguna bangunan ketika melakukan aktivitas , aktivitas yaitu menuntut ilmu dalam bidang migas di dalam dan di luar bangunan.

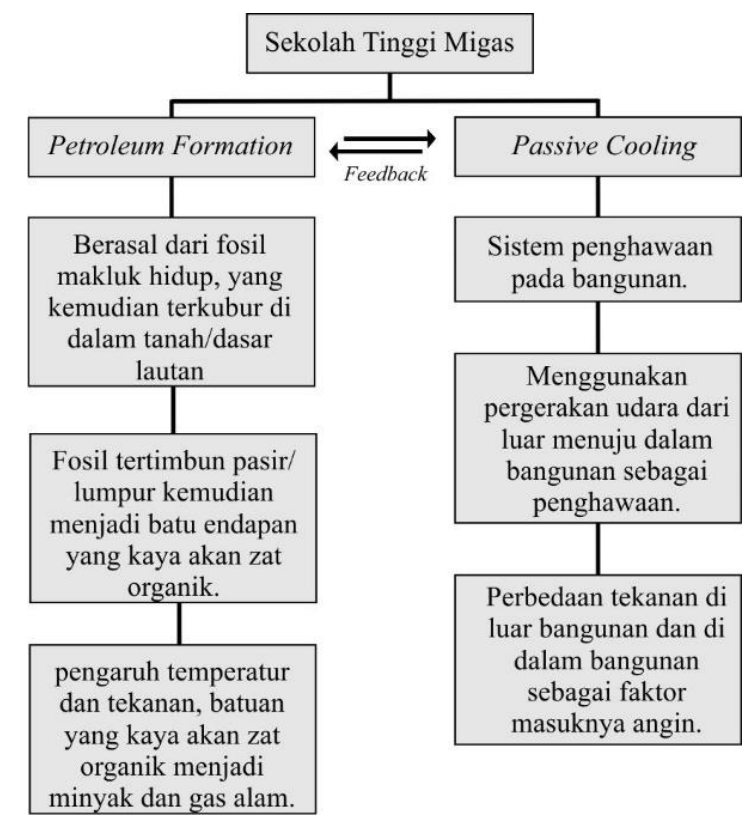

Gambar 10. Bagan Konsep

Sumber: Data Peneliti 2020

\subsubsection{Konsep Massa}

Konsep massa pada bangunan Sekolah Tinggi Migas ini diambil dari pola konsep Petroleum Formation. Petrolium Formation merupakan proses bagaimana migas bisa terbentuk, yang mana dimulai dari fosil makluk hidup yang tertimbun kedalam tanah, yang kemudian ditutupi lumpur menjadi batu endapan, dan terakhir akibat temperature suhu dan tekanan, batu endapan menjadii migas. Bentuk massa pada Sekolah Tinggi Migas ini sesuai dengan konsep perancangan, penerapan passive cooling juga di pertimbangkan di 
massa bangunan. Dikarenakan pembagian massa bangunan berdasarkan fungsi, maka akan ada lebih dari satu massa bangunan yang tidak dapat dipisahkan dari konsep perancangan.

\section{Massa Utama}

Pemilihan bentukan massa pada massa utama sebagai fungsi pendidikan ,pengelola,dan penunjang yang digabungkan menjadi satu kesatuan yang mengikat satu sama lain. Diambil dari bagaimana migas terbentuk, yang mana pada saat fosil mati dan tertimbun di dalam tanah di ceritakan sebagai bentukkan massa pengelola ,dan penunjang yang merupakan pengatur dan pemberi arahan di Sekolah Tinggi Migas sama halnya fosil merupakan bahan untuk terciptanya migas, sedangkan pada saat proses fosil yang tertimbun dan menjadi batu endapan yang kaya akan zat organik di ceritakan sebagai bentukan massa pendidikan yang mana sama halnya dengan proses batu endapan yang kaya akan zat organik dengan massa pendidikan yang kaya akan ilmu pengetahuan.

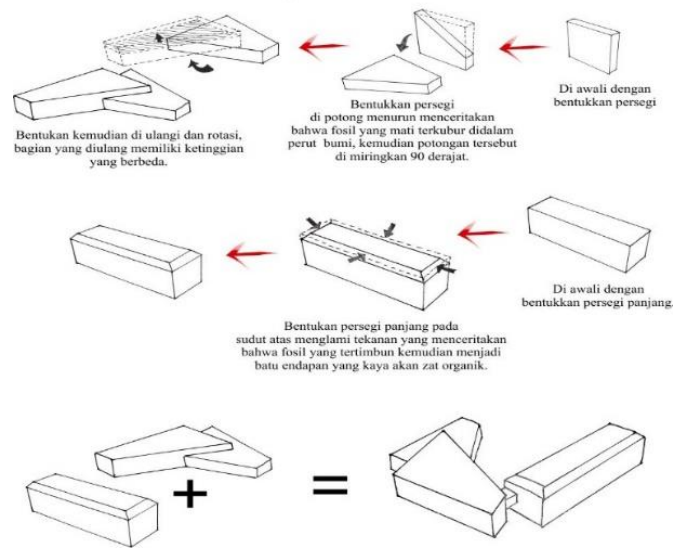

Gambar 11. Massa Utama

Sumber: Data Peneliti 2020

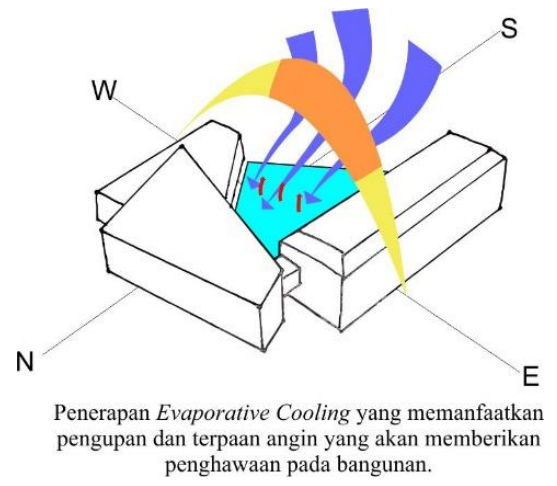

Gambar 12. Evaporative Cooling

Sumber: Data Peneliti 2020

\section{Massa Asrama}

Massa hunian di ambil dari bagaimana migas terbentuk. Pemilihan ini karena yang mana pada saat terjadi kenaikan suhu dan tekanan yang akhirnya terciptanya migas.

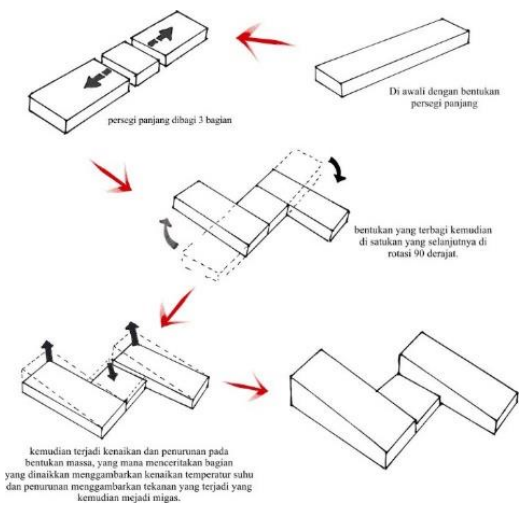

Gambar 13. Massa Asrama

Sumber: Data Peneliti 2020 


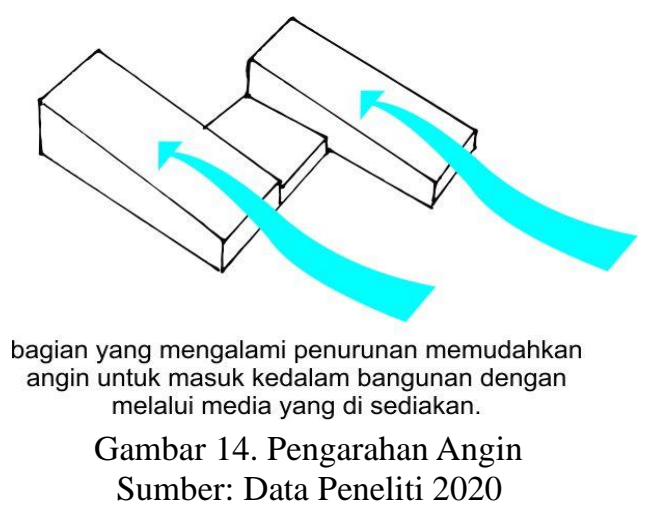

\subsubsection{Konsep Sirkulasi Luar dan Dalam}

Konsep sirkulasi pada Sekolah Tinggi Migas menggunakan bagaimana tahap produksi migas. Pola ini mengarahkan dengan tahapan produksi migas. Untuk mengakses pencapaian ke bangunan memiliki satu akses pintu masuk dan satu pintu keluar, hal ini dikarenakan untuk kemanan dan kenyamanan sekolah. Sementara untuk pencapaian parkir dibedakan menjadi parkir dosen dan pengunjung. Jalur sirkulasi dibagi menjadi, sirkulasi mobil, motor dan pejalan kaki. Untuk kemudahan bangunan Sekolah Tingi Migas ini disediakan jalur bagi pengguna disabilitas dengan penggunaan ramp dan jalur pemandu.

\subsubsection{Konsep Vegetasi}

Konsep Vegetasi pada Sekolah Tinggi Migas ini digunakan sebagai media tangkap aliran udara menuju bangunan. Dimana tanaman akan mengarahkan aliran udara dari luar bangunan menuju bangunan terutama dalam bangunan sebagai penghawaan termal yang akan memberikan kenyaman dalam beraktivitas.

Selain itu lansekap pada perancangan ini juga ditambahkan dengan tanaman-tanaman yang diletakkan berdasarkan desain dan kebutuhan. Lansekap ini juga berfungsi untuk menahan kebisingan yang berada di luar bangunan.

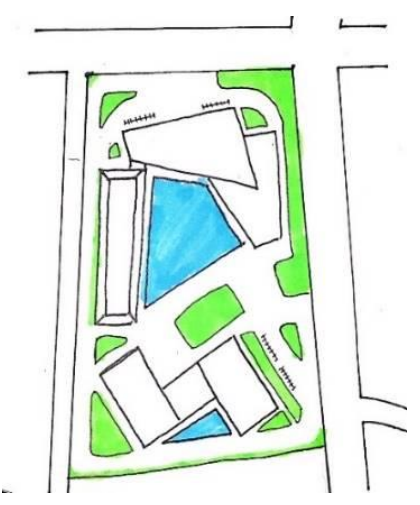

Gambar 15. Konsep Rencana Vegetasi

Sumber: Data Peneliti 2020

Jenis tanaman yang di aplikasikan dalam konsep vegetasi, yaitu :
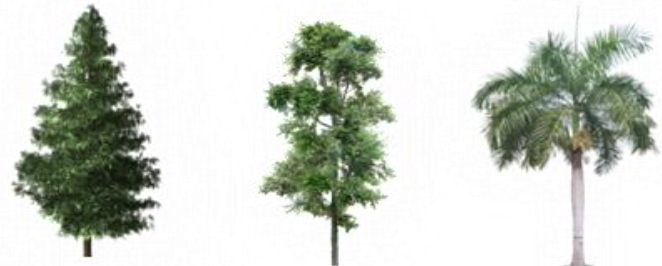

Pohon Glodogan Pohon Palem Pohon Ketapang

Gambar 16. Jenis Pohon Yang Di aplikasikan

Sumber: Data Peneliti 2020

\subsubsection{Konsep Fasad}

Konsep fasad Sekolah Tinggi Migas lebih melihat bagaimana udara bergerak ,karena fasad salah satu hal yang mempengaruhi termal pada bangunan. Gerakan udara yang di arahkan pada bangunan akan memberikan kenyamanan termal di tambah dengan pemberian vegetasi yang baik(Ghassani et al., 2020). 
Menggunakan sistem Eco Cooler adalah pilihan yang tepat karena sistem ini dapat membuat termal pada bangunan lebih nyaman.

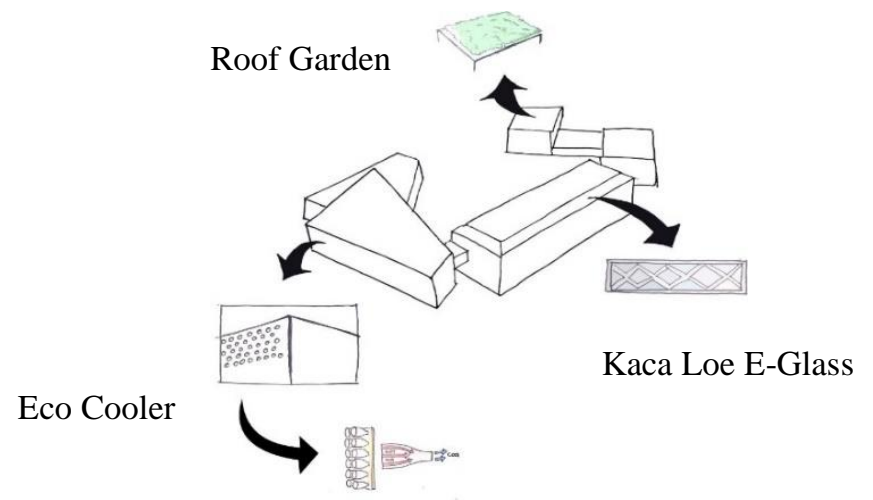

Gambar 17. Konsep Fasad

Sumber: Data Peneliti 2020

\subsubsection{Konsep Interior}

Pada interior bangunan banyak menggunakan bukaan pada sisi luar bangunan dan void pada bangunan. Pengunaan tersebut dimaksudkan untuk pergerakan udara yang akan masuk bangunan yang memberikan kenyaman pada bangunan sesuai dengan penerapan passive cooling. Interior bangunan juga menggunakan pencahayaan alami agar memaksimalkan efesiensi energy dan tempat untuk keluar udara.

\subsubsection{Penerapan Prinsip Pasif Cooling}

Prinsip desain Passive cooling berkaitan dengan penangan permasalah penghawaan pada iklim tropis. Penerapan prinsip passive cooling pada Sekolah Tinggi Migas sebagai berikut :

1. Aliran Udara

Penerapan cross ventilation yang menggunakan bukaan di dua sisi bangunan yang dapat diterapkan pada ruangan belajar mahasiswa Sekolah Tinggi Migas.
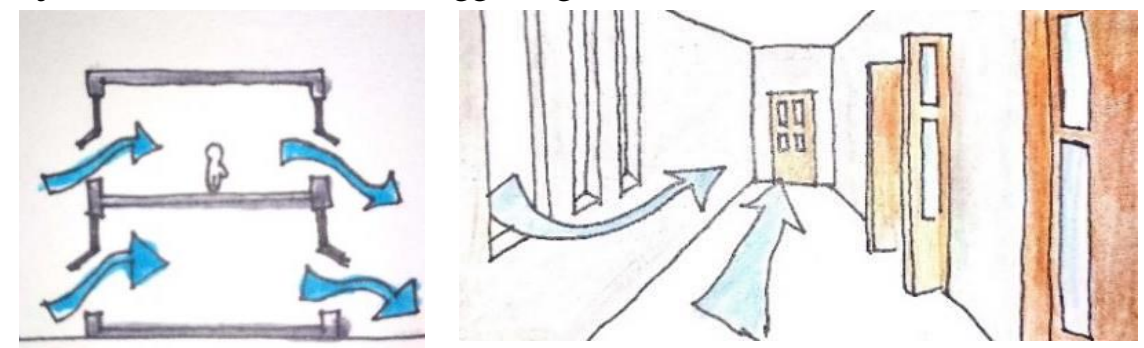

Gambar 18. Cross Ventilation

Sumber: Data Peneliti 2020

Penerapan Central Atria and Lobbies sebagai pengaliran udara dapat dimanfaatkan dengan memaksimalakn penggunaan atrium, lobby, atau void sebagai tempat masuk dan keluarnya udara.

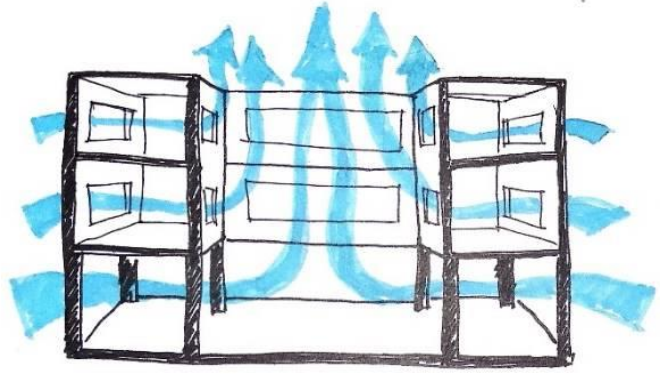

Gambar 19. Central Area And Lobbies

Sumber: Data Peneliti 2020

\section{Vegetasi}

Bangunan ditanami tanaman yang memilki karakter untuk menghalangi hawa panas dari sinar matahari dan hawa panas dari luar bangunan. Dimana vegetasi dapat mengarahkan angin kedalam bangunan. 

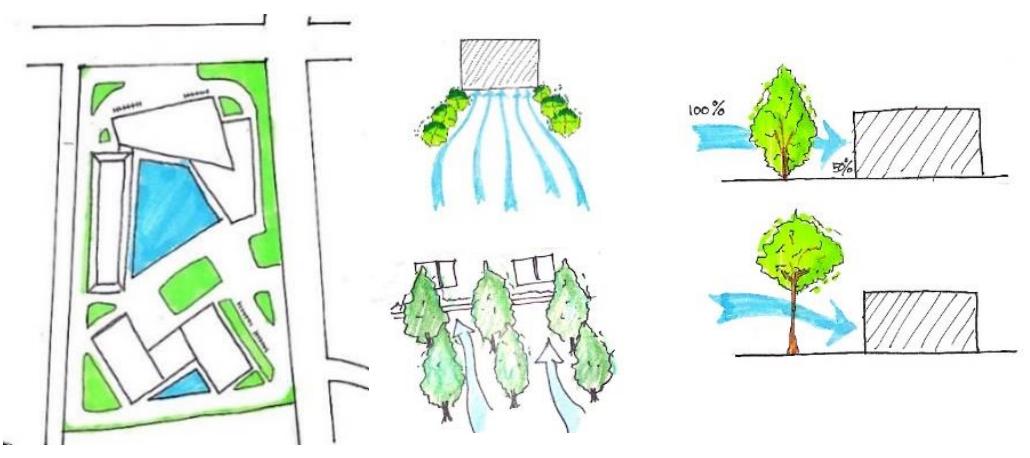

\section{Material}

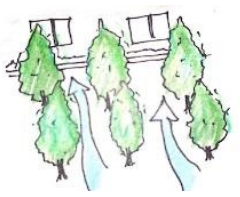

Gambar 20. Vegetasi

Sumber: Data Peneliti 2020

Penggunaan beton, kaca,dan baja pada material bangunan. Di harapkan mereduksi pengunaan energy dalam penghawaan.
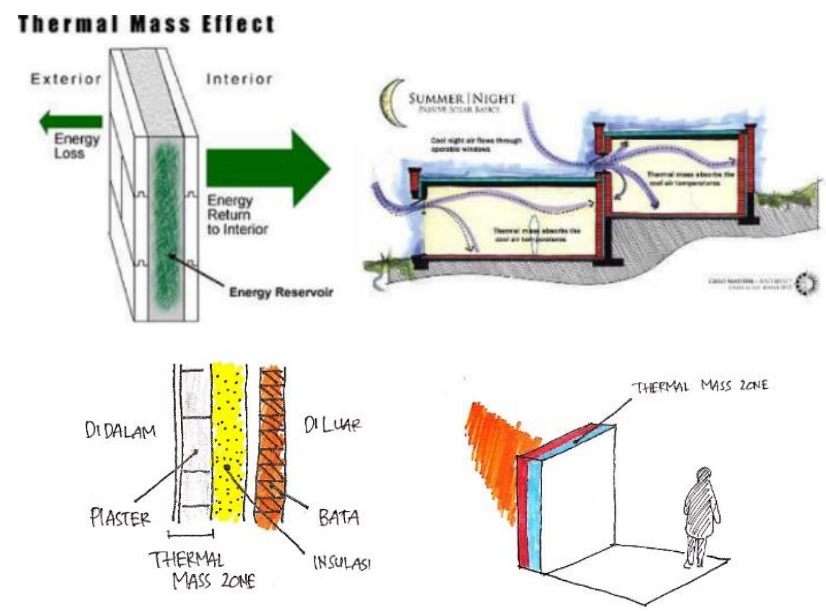

Gambar 21. Material

Sumber: Data Peneliti 2020

4. Menghindari Matahari Langsung

Dimana orientasi bangunan sangat di perhitungkan, dengan menggunakan double Fasad dan sun shading di bagian yang terkena matahri langsung diharapkan dapat memberikan kenyaman termal yang baik.
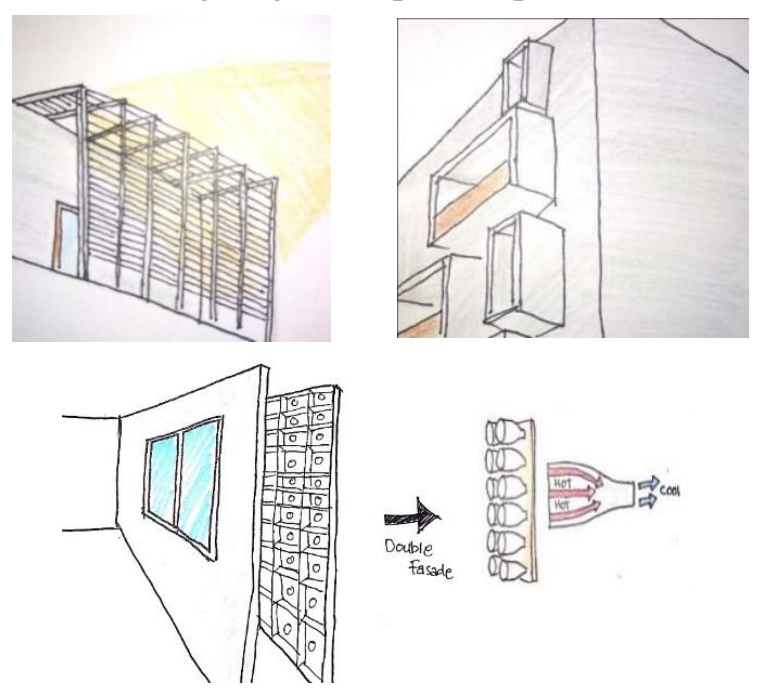

Gambar 22.Teknik Menghindari Matahari Langsung 


\section{Memanfaatkan Penguapan}

Membuat kolam khusus di sekitar bangunan sebagai penghawaan tambahan dengan sistem penguapan pada air yang dibawa masuk kedalam bangunan bersama udara.
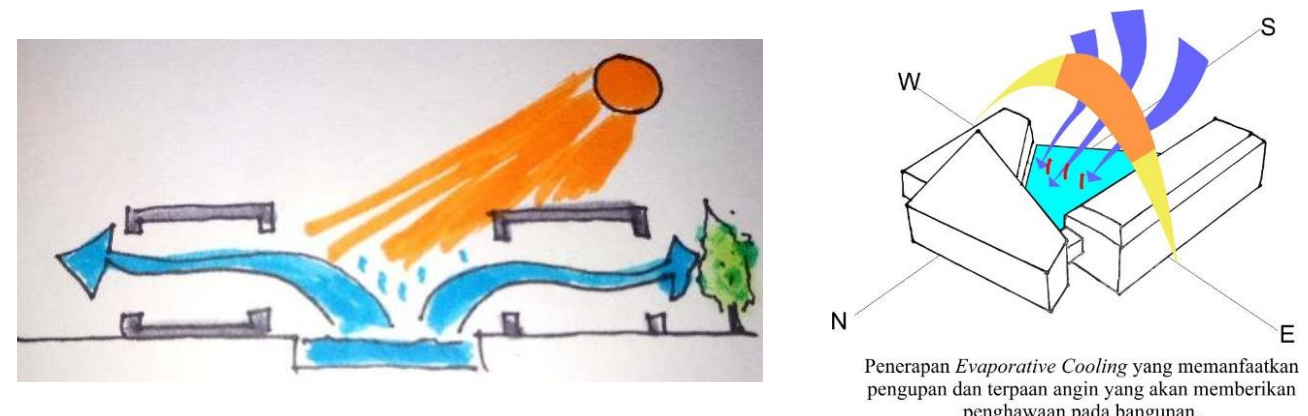

Gambar 23.Evaporative Cooling

Sumber: Data Peneliti 2020

\section{Night Ventilation}

Dengan memanfaatkan udara malam yang dingin sebagai pendingin struktur bangunan, dimana diharpakan dapat menyerap panas pada malam hari.

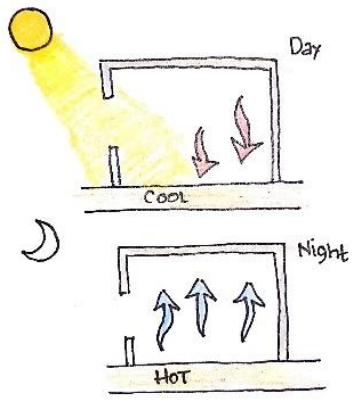

Gambar 24.Night Ventilation

Sumber: Pribadi 2020

\section{Building Shape}

Aplikasi pada building shape dan building orientation ini berdasarkan dari analisa matahari dan pertimbangan arah sinar matahari datang. Dimana bangunan di buat tidak statis agar cahaya yang masuk ke dalam bangunan bida di kendalikan.

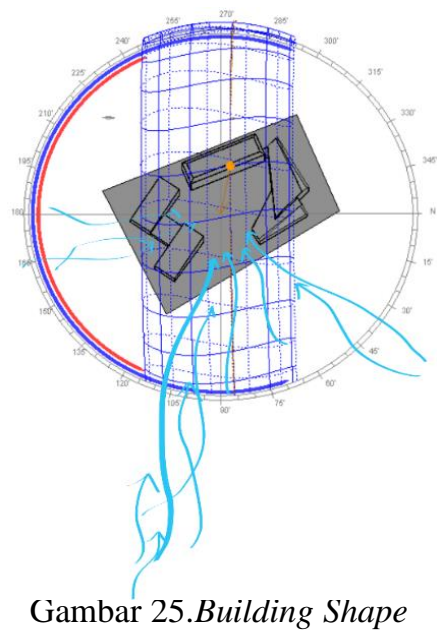

Sumber: Data Peneliti 2020

\section{Kesimpulan}

Sekolah Tinggi Migas Duri memiliki fungsi sebagai sarana pendidikan yang dikhususkan dalam bidang migas. Untuk mendukung pembelajaran yang efektif, pemilihan site berada dalam lingkungan 
komplek CPI, untuk memudahkan dalam praktek dalam bidang migas. Pada fasilitas pendidikan dilengkapi ruang pembelajaran teori dan praktek lapangan seperti laboratorium, kelas teori, perpustakaan, dll.

Penerapan prinsip passive cooling pada bangunan ini sangat tepat. Dimana Kota Duri terletak di daerah khatulistiwa yang beriklim tropis. Ada beberapa teknik pendinginan dari passive cooling yaitu night flush, memanfaatkan udara pada malam hari yang di perangkap dalam katup khusus yang digunakan pada waktu siang hari sebagai penghawaan bangunan. Penggunaan shading, hal ini bisa membuat termal bangunan jadi nyaman karena paparan cahaya matahari yang akan masuk ke dalam bangunan di suling agar hawa panas yang dibawa tidak masuk dalam bangunan. Evaporative cooler adalah teknik pendinginan dengan penguapan,dimana penggunaan kolam air di dalam bangunan sebagai sumber penguapan bagi penghawaan bangunan. Penanaman vegetasi juga dapat menghalangi panas langsung dari matahari dan mengarahkan angin ke dalam bangunan sehingga termal bangunan menjadi lebih baik.

Orientasi dari matahari dan angin sangat berpengaruh dalam pengaplikasian prinsip passive cooling. Karena pemanfaatan udara dari luar bangunan sebagai sistem penghawaan bangunan. Orientasi matahari berpengaruh terhadap termal bangunan akibiat dari hawa panas yang dibawa sinar matahari ke bangunan.

\section{Ucapan Terima Kasih}

Ucapan Terima kasih kepada dosen pembimbing yang telah membimbing penulis sampai dengan detik ini dan terimakasih kepada ketua jurusan prodi arsitektur Universitas Riau.

\section{Referensi}

Cerita lapangan duri yang jadi tulang punggung migas RI. from https://kumparan.com/kumparanbisnis/cerita-lapangan-duri-yang-60-tahun-jadi-tulang-punggungmigas-ri

Dogne, N. (2016). Passive Cooling Techniques, Design Concept and Ventilation Passive Cooling Techniques, Design Concept and. March, 4-11.

Frick, Heinz \& Suskiyatno F X. (2007). Dasar-dasar Arsitektur Ekologis: Konsep Pembangunan Berlanjutan dan Ramah Lingkungan. Semarang: Kanisius \& ITB

Ghassani, A. I., Permana, A. Y., \& Susanti, I. (2020). Konsep Ekowisata Dalam Perancangan Resort di Kabupaten Ciamis. Jurnal Arsitektur TERRACOTTA, 1(1), 1-11. https://doi.org/10.26760/terracotta.v1i1.3359

Gropius, Walter. (1955). Hearing, Cooling and Lighting. Jakarta. Rajawali Press.

Lechner, N. (2001). Heating, Cooling, Lighting, Design Methodsfor Architects, The United States of Amerika

Google Earth. (2020). Lokasi Site. From http://www.googleearth.com

Meteoblue. (2019). Data Arah dan Kecepatan Angin Kota Duri. from http://www.meteoblue.com

Peraturan Menteri Energi dan Sumber Daya Mineral Republik Iindonesia Nomor 55 Tahun 2017 Tentang Organisasi dan Tata Kerja Sekolah Tinggi Energi dan Mineral Akamigas

Prasetyo, Lilik. 2018. Rumah Susun di Pengok Yogyakarta Dengan Pendekatan Pendingin Pasif. Universitas Atma Jaya Yogyakarta. Yogyakarta

Sudiarta, I. I. N. (2016). Penghawaan Alami. Universitas Udayana, 1-24.

Vinosa, Cito. 2017. Duri Sport Centre Penekanan Pada Sistem Passive Cooling. Universitas Islam Indonesia Yogyakarta. Yogyakarta 